\title{
Disease modeling and drug screening using human airway organoids: a systematic review
}

\section{Do Hyun Kim, Sung Won Kim}

Department of Otolaryngology-Head and Neck Surgery, Seoul St. Mary’s Hospital, College of Medicine, The Catholic University of Korea, Seoul, Korea

Received: March 26, 2021

Revised: April 27, 2021

Accepted: May 15, 2021

Correspondence to:

Sung Won Kim, MD, PhD

Department of Otolaryngology-Head

and Neck Surgery, Seoul St. Mary's

Hospital, College of Medicine, The

Catholic University of Korea, 222

Banpo-daero, Seocho-gu, Seoul

06591, Korea

E-mail: kswent@catholic.ac.kr
Increasing levels of fine environmental dust particles due to industrialization and emerging respiratory illnesses, such as coronavirus disease 2019, pose serious threats to human life. The use of organoids for disease modeling and drug screening has been proposed as a new treatment approach for respiratory diseases. As discussed in this review, various pathogen models, genetic disease models, and patient-derived lung cancer organoid models have been reported for disease modeling and drug testing using human airway organoids. Despite these promising recent advances, several issues must be addressed before the disease modeling potential of human airway organoids can be fully realized. If systematic methods to produce mature airway organoids can be developed, and reproducible organoid models can be implemented using standardized protocols, airway organoids will likely become valuable respiratory disease models and drug screening tools.

Keywords: Humans; Organoids; Lung; Drug evaluation, preclinical; Mass screening

\section{Introduction}

Respiratory diseases such as asthma, chronic obstructive pulmonary disease, acute respiratory infections, tuberculosis, and lung cancer represent a large and increasing public health burden; they are associated with high morbidity and mortality, and effective treatment regimens are currently lacking [1]. Furthermore, increasing levels of fine environmental dust particles due to industrialization and emerging respiratory illnesses, such as coronavirus disease 2019 (COVID-19), pose serious threats to human life.

Organoids have received attention recently as tools for studying embryogenesis, as well as for their potential applications as disease models and transplantable mini-organs. Recent advances have facilitated the development of methods to induce cellular differentiation and generate mature respiratory organoids; these methods have provided valuable insights into the developmental mecha- nisms of the upper and lower airways [2-5]. Moreover, researchers have attempted to transplant airway organoids into animal models [6]. However, implantation models in which the organoid lumen is in direct contact with the air are difficult to generate, and clinical trials for implants developed using embryonic system cells or induced pluripotent system cells are currently limited. Therefore, recent studies have focused on using airway organoids for modeling diseases and for high-throughput drug screening [4,7-10]. In particular, during the COVID-19 pandemic, human airway models were quickly used to study the pathology of infection with severe acute respiratory syndrome coronavirus 2 (SARS-CoV-2), and drug testing was conducted to explore treatments for viral infections [11-18].

For organoids to become standard clinical in vivo mimetic models, they should ideally be derived from human cell sources. Therefore, in this review, we assessed the literature related to dis- 
ease modeling and drug screening using human airway organoids, and discussed the future development and potential directions of airway organoid research.

\section{Literature search method and selection}

We retrieved research articles from the PubMed, Cochrane Central Register of Controlled Trials and Embase databases. The search period ranged from the inception of each database until March 2021. The search terms were as follows: "organoids," "organ culture techniques," "organogenesis," "respiratory system," "nose," "trachea," "bronchi," "lung," "disease modeling," "preclinical drug evaluation," and "high-throughput." Only studies published in English were reviewed. The reference lists of included articles were examined to ensure that no relevant studies were omitted. A detailed list of the search terms and queries is presented in Table S1. The inclusion criteria for this review were as follows: human organoid research, respiratory (airway) system research, and disease modeling or drug screening studies. We excluded case reports, review articles, and articles not written in English. All abstracts and titles of candidate studies were reviewed by two independent reviewers. A search flow diagram is presented in Fig. 1.

\section{Disease modeling and drug screening research using human airway organoids}

A summary of recent studies $[7,8,10,15,19-28]$ in which human airway organoids were employed for disease modeling and drug testing is presented in Table $1[7,8,10,12,15-28]$. Since 2017, several reports of disease modeling and drug testing using human airway organoids have been published. Studies investigating the reactivity of organoids to influenza, parainfluenza, enterovirus, and various pathogenic bacteria have been conducted. Models of infections with viruses, Cryptosporidium parvum oocysts, and sporozoites were created by direct addition into organoid culture wells $[7,8,10,20,22,26,27]$. Furthermore, cystic fibrosis, a genetic disease that affects the respiratory system, and pneumonia, which also has a major genetic component, have been studied via human organoid models $[8,20,23,25,28]$. For the cystic fibrosis model, cystic fibrosis cell lines were obtained; they were made into patient-specific induced pluripotent stem cells (iPSCs) lines, and CFTR gene editing was performed to compare the results $[8,25]$. Congenital diaphragmatic hernia models were also prepared as lung organoids using iPSCs obtained from amniotic fluid and neonatal foreskin from children with congenital diaphragmatic hernia. In contrast, a model of Hermansky-Pudlak syndrome interstitial pneumonia was created with CRISPR-CAS9-induced deletion of the HPS1 gene [20]. An idiopathic pulmonary fibrosis model was created by treating fetal lung fibroblast organoids or PSC-derived mesenchymal organoids with exogenous transforming growth factor- $\beta 1$ [28]. The use of patient-derived lung cancer organoids to screen for cancer drugs is another active area of research. In the lung cancer model, lung tissue was obtained from non-small-cell lung cancer patients and these tissues were produced as organoids. Through this model, the efficacy of various anti-cancer drugs was screened [19,24]. Recently, a human organoid infection model has been developed to screen and test candidate treatments for SARS-CoV-2. Youk et al. [18] built a 3-dimensional model to grow fluorescence activated cell sorting-classified human type 2 alveolar cells and airway epithelial cells into organisms, and then split them

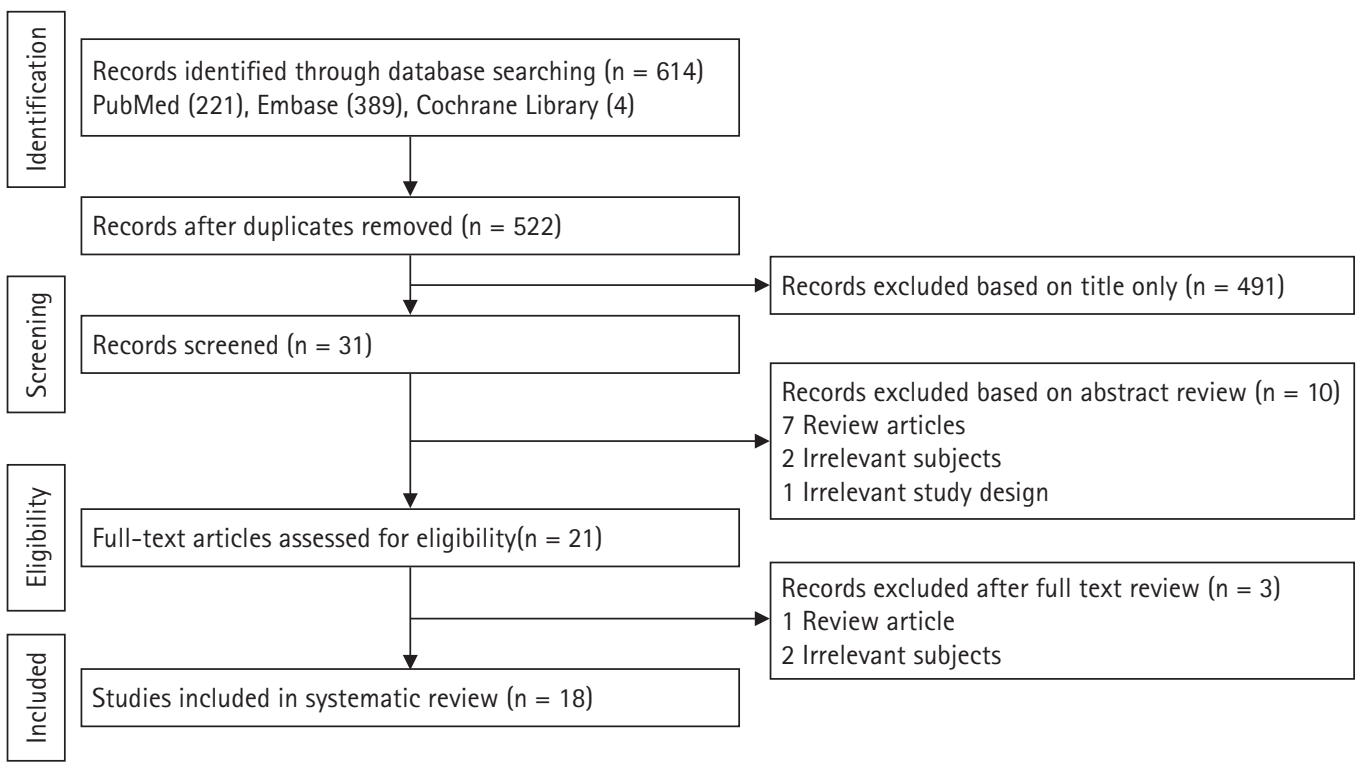

Fig. 1. Search flow diagram. 
Table 1. Details of studies on disease modeling and drug screening using human airway organoids

\begin{tabular}{|c|c|c|c|c|}
\hline Tissue/cell source & Differentiation & Disease modeling & Drug screening & Reference \\
\hline $\begin{array}{l}\text { - iPSCs from dermal fibroblasts } \\
\text { - iPSCs from cystic fibrosis } \\
\text { donor }\end{array}$ & Proximal airway organoids & $\mathrm{CF}$ & - & [25] \\
\hline Human embryonic stem cell & Lung bud organoids & $\begin{array}{l}\text { - RSV infection } \\
\text { - Hermansky-Pudlak } \\
\text { Syndrome-associated } \\
\text { interstitial pneumonia }\end{array}$ & - & [20] \\
\hline $\begin{array}{l}\text { - Human fetal lung fibroblasts } \\
\text { - iPSCs from adult lung tissue }\end{array}$ & Lung mesenchymal organoids & Idiopathic pulmonary fibrosis & - & [28] \\
\hline Lung tissue from NSCLC & Not specified & Enterovirus infection & - & [27] \\
\hline Lung tissue from NSCLC & Proximal airway organoids & Influenza virus infection & - & [10] \\
\hline Non-tumor lung tissue & Proximal airway organoids & Influenza virus infection & - & [7] \\
\hline $\begin{array}{l}\text { Bronchial airway tissue from } \\
\text { NSCLC }\end{array}$ & Lung organoids & Cryptosporidium infection & - & [22] \\
\hline - Lung tissue from NSCLC & - Proximal airway organoids & - $\mathrm{CF}$ & $\begin{array}{l}\text { Anti-cancer drugs (erlotinib, gefitinib, } \\
\text { crizotinib, methotrexate, paclitaxel, } \\
\text { nutilin-3a, alpelisib, cisplatin) }\end{array}$ & [8] \\
\hline $\begin{array}{l}\text { - Bronchoalveolar lavage fluid } \\
\text { from CF patients }\end{array}$ & - Lung tumor organoids & $\begin{array}{l}\text { - RSV infection } \\
\text { - Lung cancer }\end{array}$ & & \\
\hline Human embryonic stem cells & Lung bud organoids & $\begin{array}{l}\text { - HPIV3 } \\
\text { - Recombinant measles virus }\end{array}$ & - & [26] \\
\hline $\begin{array}{l}\text { - iPSCs from amniotic fluid and } \\
\text { neonatal foreskin } \\
\text { - Fetal/neonatal lung tissue }\end{array}$ & Lung organoids & $\begin{array}{l}\text { Bochdalek congenital } \\
\text { diaphragmatic hernia }\end{array}$ & - & [23] \\
\hline Lung cancer tissue from NSCLC & Lung cancer organoids & NSCLC & $\begin{array}{l}\text { Chelerythrine chloride, cantharidin, } \\
\text { harmine, betaine, berberine compounds }\end{array}$ & [24] \\
\hline Lung cancer tissue from NSCLC & Lung cancer organoids & NSCLC & $\begin{array}{l}\text { Anti-cancer drugs (EGFR-TKIs a) and } \\
\text { chemotherapy drugs }{ }^{\text {b) }} \text { ) }\end{array}$ & [19] \\
\hline Lung tissue & Alveolar organoids & SARS-CoV-2 infection & - & [18] \\
\hline Lung tissue & $\begin{array}{l}\text { - Proximal airway epithelial } \\
\text { cells } \\
\text { - Alveolar organoids }\end{array}$ & SARS-CoV-2 infection & - & [17] \\
\hline Lung tissue & $\begin{array}{l}\text { - Proximal airway epithelial } \\
\text { cells } \\
\text { - Alveolar organoids }\end{array}$ & $\begin{array}{l}\text { - SARS-CoV-2 infection } \\
\text { - Influenza virus H1N1 }\end{array}$ & Zanamivir & [16] \\
\hline Human embryonic stem cells & Lung organoids & SARS-CoV-2 infection & $\begin{array}{l}\text { Imatinib, mycophenolic acid, quinacrine } \\
\text { dihydrochloride }\end{array}$ & [21] \\
\hline Human embryonic stem cells & Lung organoids & SARS-CoV-2 infection & $\begin{array}{l}\text { Imatinib, mycophenolic acid, quinacrine } \\
\text { dihydrochloride }\end{array}$ & [12] \\
\hline $\begin{array}{l}\text { Lung tissue from deceased organ } \\
\text { donors }\end{array}$ & $\begin{array}{l}\text { - Proximal airway epithelial } \\
\text { cells } \\
\text { - Alveolar organoids }\end{array}$ & SARS-CoV-2 infection & Hydroxychloroquine, remdesivir & [15] \\
\hline
\end{tabular}

iPSCs, induced pluripotent stem cells; CF, cystic fibrosis; RSV, respiratory syncytial virus; NSCLC, non-small cell lung cancer; HPIV, human parainfluenza virus; EGFR-TKIs, epidermal growth factor receptor tyrosine kinase inhibitors; SARS-CoV-2, severe acute respiratory syndrome coronavirus 2.

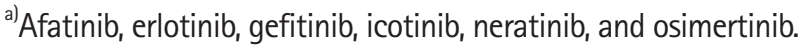

${ }^{b}$ Methotrexate, cytarabine, cisplatin, carboplatin, docetaxel, etoposide, gemcitabine, irinotecan, paclitaxel, pemetrexed, topotecan, vincristine, vinorelbine, and cephalomannine.

into pieces to enhance viral access to the apical cell surfaces. Tindle et al. [17] were able to established airway organoids with six epithelial cell types from the distal human lungs. These included type 1 and 2 alveolar cells, basal cells, club cells, goblet cells, and ciliated cells. Salahudeen et al. [16] developed chemically-defined culture protocols that could produce type 2 alveolar organoids and 
solid basal organoids with lumens. Han et al. [12,21] generated lung organoids that produced inflammatory reactions mimicking human COVID-19 infections, and tested high-throughput screening for US Food and Drug Administration-approved drugs and drugs known to inhibit SARS-CoV-2 entry. Mulay et al. [15] found that SARS-CoV-2 infection caused cell-autonomous and non-cell-autonomous cell death that could contribute to alveolar damage. They also found the virus targeted mainly ciliated cells in the airway. Candidates for the treatment of SARS-CoV-2 using airway organoids were imatinib, mycophenolic acid, quinacrine dihydrochloride, hydroxychloroquine, and remdesivir [15,21].

\section{Limitations and future directions}

Over recent years, methods for culturing airway organoids to investigate respiratory organogenesis have been well established [29,30]. Therefore, we focused on disease modeling and drug screening using airway organoids for this review, which demonstrated that multiple studies have been performed using organoids in various fields of respiratory research in recent years. For example, human organoids have been infected with bacteria and viruses in various studies, which confirmed their similarity to in vivo models; similar studies were conducted to test drug candidates. In addition, disease modeling using patient-derived cells to generate organoids has been performed and applied to the study of congenital and genetic diseases, as well as lung cancer. Organoid drug screening studies to develop effective treatments for SARS-CoV-2 are also in progress.

Despite these promising recent advances, several issues must be addressed before the disease modeling potential of human airway organoids can be fully realized. For example, the complete differentiation of human PSCs into specialized airway types is highly challenging, particularly for the differentiation of AEC1 cells and alveolar-like cell arrays [29]. To overcome this, researchers are exploring the possibility of using kidney capsules harvested from immunodeficient mice as niches to facilitate organoid maturation [9]. Another limitation of organoid models is their lack of reproducibility. This must be improved to establish organoids as reliable disease models, but doing so will require standardization of the organoid production process and the development of systematic high-throughput mass-screening tools. Accordingly, high- throughput processes are currently being developed to produce human airway organoids [31]. Moreover, the culture media used to induce organoids typically contain complex supplements, such as bovine extract or mouse sarcoma derivatives. Xenogenic-free, chemically-defined media are currently being developed $[8,16,18,32]$ to further simplify and standardize the organoid production process.

Organoids are often referred to as "mini-organs"; however, it is currently challenging to produce large and complex structures with realistic organ sizes. When organoids reach a certain size threshold, the internal cells often undergo necrosis due to limitations in nutrient and oxygen exchange. To overcome this, bioengineered scaffolds are currently being developed [33]. During intestinal and respiratory organoid development, lumens form inside the spherical organoid structures. Physiological responses may differ between the respiratory system, which elicits immune responses to external substances detected by the epithelium, and the airway organoids, in which the apical lumen is situated within the spherical organoid structure. Techniques such as microinjection [26], cell shearing using Pasteur pipettes [7], enzymatic dissociation, organoid culture using a two-dimensional format [10] and apical-outward structure development using bioengineered niches [34] have been developed to mitigate these physiological differences.

Lastly, disease modeling and drug screening with organoids are currently limited to rare respiratory diseases with a relatively simple genetic basis. This has impeded organoid research using well-established models, such as asthma and chronic obstructive pulmonary disease, which are difficult to implement due to their complex etiology. In addition, efforts should be made to generate a cancer organoid model that is well integrated within a vascular structure to better reflect in vivo systems; current simple cancer organoid models comprise only cancer cells and surrounding fibroblasts.

\section{Conclusion}

The respiratory system, consisting of the upper and lower airways, is formed when the ectodermal and endodermal layers join together during embryogenesis; a key advantage of airway organoid models is that they include both developmental systems. If systematic methods to produce mature airway organoids can be developed, and reproducible organoid models can be implemented using standardized protocols, airway organoids will likely become valuable respiratory disease models and drug screening tools capable of replacing animal models for in vivo-mimicking in vitro studies.

\section{Supplementary Information}

Supplementary materials are presented online (available at https:// doi.org/10.51335/organoid.2021.1.e8).

\section{Notes}

\section{Conflict of interest}

Sung Won Kim has been an editor of Organoid since 2021. No other potential conflict of interest relevant to this article was reported. 


\section{Funding}

This research was supported by the Basic Science Research Program through the National Research Foundation of Korea (NRF) funded by the Ministry of Education (2020R1I1A1A01051844) and the Bio \& Medical Technology Development Program of the NRF funded by the Ministry of Science \& ICT (2019M3A9H 2032424, 2019M3E5D5064110). The sponsors had no role in the study design, data collection and analysis, decision to publish, or preparation of the manuscript.

\section{Additional contributions}

We thank Na Jin Kim (Medical Library, The Catholic University of Korea, Seoul, Republic of Korea) for help developing the search terms/queries and searching databases.

\section{ORCID}

Do Hyun Kim, https://orcid.org/0000-0002-9248-5572

Sung Won Kim, https://orcid.org/0000-0002-8981-2536

\section{REFERENCES}

1. Ferkol T, Schraufnagel D. The global burden of respiratory disease. Ann Am Thorac Soc 2014;11:404-6.

2. Hogan BL, Barkauskas CE, Chapman HA, Epstein JA, Jain R, Hsia CC, et al. Repair and regeneration of the respiratory system: complexity, plasticity, and mechanisms of lung stem cell function. Cell Stem Cell 2014;15:123-38.

3. Huang SX, Green MD, de Carvalho AT, Mumau M, Chen YW, D'Souza SL, et al. The in vitro generation of lung and airway progenitor cells from human pluripotent stem cells. Nat Protoc 2015;10:413-25.

4. Hynds RE, Butler CR, Janes SM, Giangreco A. Expansion of human airway basal stem cells and their differentiation as 3D tracheospheres. Methods Mol Biol 2019;1576:43-53.

5. Kotton DN, Morrisey EE. Lung regeneration: mechanisms, applications and emerging stem cell populations. Nat Med 2014;20:822-32.

6. Miller AJ, Hill DR, Nagy MS, Aoki Y, Dye BR, Chin AM, et al. In vitro induction and in vivo engraftment of lung bud tip progenitor cells derived from human pluripotent stem cells. Stem Cell Reports 2018;10:101-19.

7. Hui KPY, Ching RHH, Chan SKH, Nicholls JM, Sachs N, Clevers $\mathrm{H}$, et al. Tropism, replication competence, and innate immune responses of influenza virus: an analysis of human airway organoids and ex-vivo bronchus cultures. Lancet Respir Med 2018;6:846-54.

8. Sachs N, Papaspyropoulos A, Zomer-van Ommen DD, Heo I,
Böttinger L, Klay D, et al. Long-term expanding human airway organoids for disease modeling. EMBO J 2019;38:e100300.

9. Tan Q Choi KM, Sicard D, Tschumperlin DJ. Human airway organoid engineering as a step toward lung regeneration and disease modeling. Biomaterials 2017;113:118-32.

10. Zhou J, Li C, Sachs N, Chiu MC, Wong BH, Chu H, et al. Differentiated human airway organoids to assess infectivity of emerging influenza virus. Proc Natl Acad Sci U S A 2018; 115:6822-7.

11. Duan F, Guo L, Yang L, Han Y, Thakur A, Nilsson-Payant BE, et al. Modeling COVID-19 with human pluripotent stem cell-derived cells reveals synergistic effects of anti-inflammatory macrophages with ACE2 inhibition against SARS-CoV-2 [Preprint]. Res Sq 2020:rs.3.rs-62758. Posted 2020 Aug 20. https://doi.org/10.21203/rs.3.rs-62758/v1.

12. Han Y, Duan X, Yang L, Nilsson-Payant BE, Wang P, Duan F, et al. Identification of SARS-CoV-2 inhibitors using lung and colonic organoids. Nature 2021;589:270-5.

13. Huang J, Hume AJ, Abo KM, Werder RB, Villacorta-Martin C, Alysandratos KD, et al. SARS-CoV-2 infection of pluripotent stem cell-derived human lung alveolar type 2 cells elicits a rapid epithelial-intrinsic inflammatory response. Cell Stem Cell 2020;27:962-73.

14. Lu T, Cao Y, Zhao P, Shen S, Xi Y. Organoid: a powerful tool to study lung regeneration and disease. Cell Regen 2021;10:21.

15. Mulay A, Konda B, Garcia G Jr, Yao C, Beil S, Villalba JM, et al. SARS-CoV-2 infection of primary human lung epithelium for COVID-19 modeling and drug discovery. Cell Rep 2021;35:109055.

16. Salahudeen AA, Choi SS, Rustagi A, Zhu J, van Unen V, de la O SM, et al. Progenitor identification and SARS-CoV-2 infection in human distal lung organoids. Nature 2020;588:670-5.

17. Tindle C, Fuller M, Fonseca A, Taheri S, Ibeawuchi SR, Beutler $\mathrm{N}$, et al. Adult stem cell-derived complete lung organoid models emulate lung disease in COVID-19. Elife 2021;10:e66417.

18. Youk J, Kim T, Evans KV, Jeong YI, Hur Y, Hong SP, et al. Three-dimensional human alveolar stem cell culture models reveal infection response to SARS-CoV-2. Cell Stem Cell 2020;27:905-19.

19. Chen JH, Chu XP, Zhang JT, Nie Q, Tang WF, Su J, et al. Genomic characteristics and drug screening among organoids derived from non-small cell lung cancer patients. Thorac Cancer 2020;11:2279-90.

20. Chen YW, Huang SX, de Carvalho A, Ho SH, Islam MN, Volpi $\mathrm{S}$, et al. A three-dimensional model of human lung development and disease from pluripotent stem cells. Nat Cell Biol 2017;19:542-9. 
21. Han Y, Yang L, Duan X, Duan F, Nilsson-Payant BE, Yaron TM, et al. Identification of candidate COVID-19 therapeutics using hPSC-derived lung organoids [Preprint]. Posted 2020 May 5. bioRxiv 2020.05.05.079095. https://doi.org/ 10.1101/2020.05.05.079095.

22. Heo I, Dutta D, Schaefer DA, Iakobachvili N, Artegiani B, Sachs $\mathrm{N}$, et al. Modelling Cryptosporidium infection in human small intestinal and lung organoids. Nat Microbiol 2018;3:814-23.

23. Kunisaki SM, Jiang G, Biancotti JC, Ho KKY, Dye BR, Liu AP, et al. Human induced pluripotent stem cell-derived lung organoids in an exvivo model of the congenital diaphragmatic hernia fetal lung. Stem Cells Transl Med 2021;10:98-114.

24. Li YF, Gao Y, Liang BW, Cao XQ, Sun ZJ, Yu JH, et al. Patient-derived organoids of non-small cells lung cancer and their application for drug screening. Neoplasma 2020;67:430-7.

25. McCauley KB, Hawkins F, Serra M, Thomas DC, Jacob A, Kotton DN. Efficient derivation of functional human airway epithelium from pluripotent stem cells via temporal regulation of Wnt signaling. Cell Stem Cell 2017;20:844-57.

26. Porotto M, Ferren M, Chen YW, Siu Y, Makhsous N, Rima B, et al. Authentic modeling of human respiratory virus infection in human pluripotent stem cell-derived lung organoids. mBio 2019; 10:e00723.

27. van der Sanden S, Sachs N, Koekkoek SM, Koen G, Pajkrt D, Clevers H, et al. Enterovirus 71 infection of human airway organoids reveals VP1-145 as a viral infectivity determinant. Emerg Microbes Infect 2018;7:84.

28. Wilkinson DC, Alva-Ornelas JA, Sucre JM, Vijayaraj P, Durra A, Richardson W, et al. Development of a three-dimensional bioengineering technology to generate lung tissue for personalized disease modeling. Stem Cells Transl Med 2017;6:622-33.

29. Barkauskas CE, Chung MI, Fioret B, Gao X, Katsura H, Hogan BL. Lung organoids: current uses and future promise. Development 2017;144:986-97.

30. Lee JH, Tammela T, Hofree M, Choi J, Marjanovic ND, Han S, et al. Anatomically and functionally distinct lung mesenchymal populations marked by Lgr5 and Lgr6. Cell 2017;170:114963.

31. Hild M, Jaffe AB. Production of 3-D airway organoids from primary human airway basal cells and their use in high-throughput screening. Curr Protoc Stem Cell Biol 2016;37:IE.9.1-15.

32. Aisenbrey EA, Murphy WL. Synthetic alternatives to Matrigel. Nat Rev Mater 2020;5:539-51.

33. Dye BR, Dedhia PH, Miller AJ, Nagy MS, White ES, Shea LD, et al. A bioengineered niche promotes in vivo engraftment and maturation of pluripotent stem cell derived human lung organoids. Elife 2016;5:e19732.

34. Iverson E, Kaler L, Agostino EL, Song D, Duncan GA, Scull MA. Leveraging 3D model systems to understand viral interactions with the respiratory mucosa. Viruses 2020;12:1425. 